\title{
Effect of Cu Cladding on the Mechanical Properties of Iron Sheath Material in the Drawing of Superconducting $\mathrm{MgB}_{2}$ Wires
}

\author{
Niyaz Ahamad Madhar ${ }^{1}$, Mohammed Shahabuddin ${ }^{1, *}$, Monis Luqman ${ }^{2}$, Taha Bilal ${ }^{1}$, \\ Nasser S. Alzayed ${ }^{1}\left(\mathbb{D}\right.$ and Mohammad Asif ${ }^{3}$ (D) \\ 1 Department of Physics and Astronomy, College of Science, King Saud University, PO Box 2455, Riyadh 11451, \\ Saudi Arabia; nmadhar@ksu.edu.sa (N.A.M.); tahabilal00@gmail.com (T.B.); nalzayed@ksu.edu.sa (N.S.A.) \\ 2 Department of Mechanical Engineering, King Saud University, Riyadh 11421, Saudi Arabia; \\ monisluqman9@gmail.com \\ 3 Department of Chemical Engineering, King Saud University, PO Box 800, Riyadh 11421, Saudi Arabia; \\ masif@ksu.edu.sa \\ * Correspondence: mshahab@ksu.edu.sa; Tel.: +966-55-422-4762
}

Received: 23 September 2019; Accepted: 3 November 2019; Published: 6 November 2019

check for updates

\begin{abstract}
In the present study, a novel choice of sheath materials for drawing long superconducting $\mathrm{MgB}_{2}$ wire by using the powder-in-tube technique (PIT) is reported. This would eliminate the need for an intermediate strain-relieving annealing process and would reduce the time and cost of fabrication. Our strategy involved the use of a composite sheath instead of a sheath made of a single material. The relatively inert Fe constituted the inner sheath around the $\mathrm{MgB}_{2}$ powder while the $\mathrm{Cu}$-which is capable of efficient heat dissipation-was used as the outer sheath. Important mechanical properties of the wire such as elastic modulus, ultimate tensile strength, yield strength, hardness, and microstructure were carefully studied at different stages of the drawing process using tensile and microhardness tests. To clearly delineate the effect of $\mathrm{Cu}$ cladding on the ductile behavior of the iron sheath, another $\mathrm{MgB}_{2}$ wire with only an Fe sheath was prepared; its mechanical properties were measured and compared with those of the composite $\mathrm{Cu}-\mathrm{Fe}$-sheathed $\mathrm{MgB}_{2}$ wire. After a few drawing steps, the composite $\mathrm{Cu}-\mathrm{Fe}$-sheathed wire showed a lower elastic modulus and tensile strength than those of its Fe sheath counterpart. While both types of wires showed an increase in hardness as the drawing process progressed, the composite-sheath wire consistently showed a lower hardness than that of its counterpart, implying its lower susceptibility to fracture; it can therefore be safely drawn to small diameters without the need for intermediate annealing during the wire drawing process.
\end{abstract}

Keywords: $\mathrm{MgB}_{2}$ wire; powder-in-tube technique; composite $\mathrm{Cu}-\mathrm{Fe}$ sheath; tensile stress; microhardness

\section{Introduction}

The discovery of superconductivity in $\mathrm{MgB}_{2}$ in 2001 has opened new avenues of research and application of this material due to its relatively high $\mathrm{T}_{\mathrm{C}}$, light weight, the low cost of its constituent materials, and the absence of weak links [1-7]. However, its large-scale commercial application depends upon the production of long wires with sufficiently high current carrying capacity using low-cost production methods. Since $\mathrm{MgB}_{2}$ is ceramic in nature, (in situ/ex situ) powder-in-tube (PIT) is one of the simplest methods for producing cost-effective wires [8]. In the PIT process, powder is first loaded into a metal tube and the composite assembly is mechanically worked using conventional metal working processes to produce long wires or tapes. Metal tubes, also called sheath metal, should be 
ductile and chemically compatible with $\mathrm{MgB}_{2}$ [9]. In spite their chemical suitability as sheath materials, expensive inert materials such as niobium or tantalum are not cost-effective [10]. On the other hand, low-cost iron sheaths are found to be less reactive during the sintering process in the range of 600 to $900{ }^{\circ} \mathrm{C}$ during the formation of $\mathrm{MgB}_{2}$. Moreover, they possess good ductility and mechanical strength for improving compaction of the $\mathrm{MgB}_{2}$ core during the deformation of the wire [11].

Producing long conductors requires extensive elongation of the sheath metals using processes such as swaging, wire drawing, and rolling. It is well known that plastic deformation induced by conventional forming methods such as swaging, rolling, drawing or extrusion can significantly change the mechanical properties of metals. Although these processes increase the strength, this increase in strength is nonetheless usually accompanied by the loss of ductility, making the sample prone to fracture as the number of dislocations increases.

The detrimental effects of heavy mechanical deformation may be compensated by intermediate strain-relieving annealing steps carried out at suitable temperatures for suitable durations. However, while manufacturing $\mathrm{MgB}_{2}$ wires, it is generally not desirable to perform heat treatment processes between sequential steps of the deformation for two main reasons: First, the softening of the matrix material leads to less effective compaction of the powder and a less homogenous boundary between the powder and the tube. Second, for some matrix materials such as iron, the annealing temperature is either close to or above the temperature at which its reaction with the superconducting core starts to take place [12,13]. Another issue is the heat dissipation from the superconducting wires during actual practical operations. Copper, which has a much higher thermal conductivity $(401 \mathrm{~W} /(\mathrm{m} \cdot \mathrm{K}))$ than that of iron $(80.4 \mathrm{~W} /(\mathrm{m} \cdot \mathrm{K}))$ [14], can efficiently dissipate heat if used as a sheath metal. However, this aspect of copper as an ideal sheath material is severely compromised due its high reactivity with the $\mathrm{MgB}_{2}$ superconducting powder [15].

In light of the above, we set out to develop a novel cost-effective wire processing technique for the reduction of size to as low as $1 \mathrm{~mm}$ without breaking which does not require intermediate strain-relief annealing. To this end, we devised a composite sheath by covering the inner iron sheath around the powder with a copper cladding. This strategy provided the strong mechanical support of the relatively inert iron while the copper cladding facilitated the efficient dissipation of the heat produced during the wire drawing process. Since sheath hybridization obviates the intermediate annealing step, it would substantially reduce processing time and greatly enhance the cost-effectiveness of the wire fabrication process. Moreover, even during an actual operation, $\mathrm{MgB}_{2}$ wire with a composite copper/iron sheath will be very effective in dissipating heat.

\section{Experimental Section}

Superconducting wires were fabricated using a PIT technique with ex situ $\mathrm{MgB}_{2}$ powder $(99.0 \%$ Alfa Aesar) by using a composite copper/iron sheath. In the ex situ technique, the tube is filled with commercial $\mathrm{MgB}_{2}$ powder and is subjected to a stepwise drawing process to achieve the desired diameter. We used iron tubes with inner and outer diameters of 7 and $10 \mathrm{~mm}$ respectively; those of the copper tubes were 10 and $12 \mathrm{~mm}$ respectively. Both tubes were obtained from Goodfellow (UK) and were $99.9 \%$ pure. The iron tube was first fitted into the copper tube, and one of the two open ends was closed using Teflon. The ex situ $\mathrm{MgB}_{2}$ powder was poured and packed tightly into this copper-clad iron tube, and the second end was closed with Teflon. We fabricated another batch of wires without the outer copper sheath for the comparison of mechanical properties during the intermediate stages of the wire drawing process.

The metal tubes with $\mathrm{MgB}_{2}$ powder packed inside were first uniformly radially hammered using a swaging machine to tightly bind the powder with the sheath while simultaneously uniformly reducing the tube diameter with a fine finishing. This technique helped to reduce the outer tube diameter from 12 to $8 \mathrm{~mm}$ in steps of $0.5 \mathrm{~mm}$ between each reduction process. Using a bench-type wire drawing machine, the specimens were then drawn into wires by further reducing their diameter. In this technique, the tubes were pulled through diamond-coated dies in order to reduce their diameters according to 
the sizes of the dies. Approximately 10\% reduction in the cross-sectional area takes place in each step of drawing. We continued the wire drawing process without annealing. A starting length of approximately $70 \mathrm{~cm}$ was used in order to obtain three specimens of $10 \mathrm{~cm}$ each from the same wire at different stages of drawing. To answer the question of why the composite $\mathrm{Cu} / \mathrm{Fe}$ sheath is easier to draw without intermediate annealing processes, we compared the mechanical properties of the iron sheaths in both types of wires. The mechanical properties were measured as functions of the outer diameter of the iron sheath for both types of samples. In the cases of the composite $\mathrm{Cu} / \mathrm{Fe}$ samples, the $\mathrm{Cu}$ cladding was mechanically removed. All measurements were carried out at room temperature. The mechanical properties were calculated from the engineering stress and strain measurements, obtained using the Universal Testing System by Instron (Model 5984, Norwood, MA, USA), with load cell serial number 105860 . The load cell has a measurement accuracy of $0.4 \%$ in force and $0.05 \%$ in displacement. The engineering stress and strain measurements were carried out on three specimens of the each sample, and the results were averaged and reported. The standard errors of measurement were in the range of $3 \%$ to $4 \%$ and are shown as error bars in the figures.

For microhardness measurements, $2 \mathrm{~cm}$ long specimens were obtained from the sample wires and fixed in a $2.5 \mathrm{~cm}$ diameter tube with the help of transparent epoxy while exposing the sample cross-section, as shown in Figure 1. Three samples each of Fe-sheathed and composite $\mathrm{Cu} / \mathrm{Fe}$-sheathed wire were cut from the same starting wire samples at different stages of drawing. Microhardness was measured for only the iron sheath in each case. The thickness of the iron sheath was much larger than the area of indentation and hardness measurement rules were followed. The black central region of each wire is the $\mathrm{MgB}_{2}$ core.

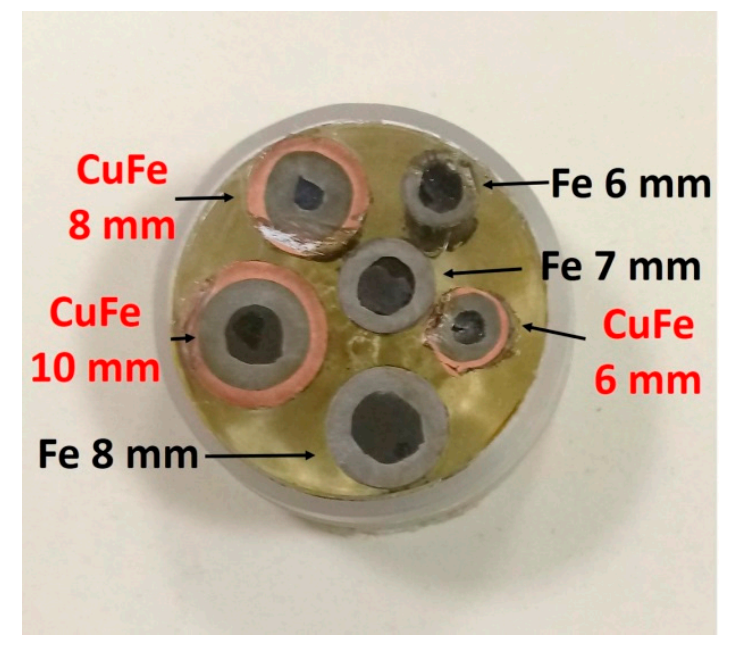

Figure 1. Cross-section of composite $\mathrm{Cu}$-Fe-sheathed and $\mathrm{Fe}$-sheathed $\mathrm{MgB}_{2}$ wire loaded onto a stub for hardness measurement.

The surface grinding and polishing of the cross section of the wire samples was done using a Metaserv-250 grinder-polisher machine supplied by Buehler. Each sample was polished with diamond-suspended paste on a polishing mat. The characterization data was not affected by the geometry of the sample arrangement for the polishing. After performing the above procedure, a Vicker microhardness test was performed on each sample using a microhardness testing machine from Zwick Roell-Indentec, Brierley Hill, UK. The measurement was done with $300 \mathrm{~g}$ of force and a $10 \mathrm{~s}$ indentation time. A minimum of five readings was taken for each sample to compute the average value.

In order to understand the mechanism behind the easy drawing of $\mathrm{Cu}-\mathrm{Fe}$ sheath material, microstructure studies of the Fe-sheaths were carried out on both types of samples at different stages of drawing. Chemical etching of the metal is required in order to see the grain boundaries and the sizes of the grains. In our study, the chemical etching of iron in all of the polished samples seen in Figure 1 was carried out using a nital solution. Optical images of the etched polished surface were 
obtained using a metallographic optical microscope (Model BX51RF Olympus Corporation, Tokyo, Japan) to study the grain structures of all samples.

\section{Results and Discussion}

As mentioned earlier, we carefully fabricated two different kinds of superconducting $\mathrm{MgB}_{2}$ wire samples: Those with $\mathrm{Fe}$ sheaths and those with composite $\mathrm{Cu}-\mathrm{Fe}$ sheaths. For characterization, three specimens of each sample were cut from both types of wires at different stages of the drawing process. In the following, we report the mechanical properties of the sheath as functions of diameter reduction, which of course depends upon the number of drawing steps, i.e., the amount of cold work done on the material.

First, we show the engineering stress-strain curves for three different cases of composite $\mathrm{Cu} / \mathrm{Fe}$-sheathed $\mathrm{MgB}_{2}$ wires in Figure 2. Note that we started with wire with an outer diameter of $12 \mathrm{~mm}$, which was gradually reduced to $6 \mathrm{~mm}$. The required numbers of drawing steps were 4,6 and 10 for reducing the size from $12 \mathrm{~mm}$ to 10,8 and $6 \mathrm{~mm}$, respectively. The outer diameters of the Fe sheath in these samples were 8,6 , and $4 \mathrm{~mm}$, respectively. These diameters are mentioned in the legend in Figure 2. The $8 \mathrm{~mm}$ sample shows a much slower response to the change in stress beyond its ultimate tensile strength (UTS). However, decreasing the diameter to $4 \mathrm{~mm}$ greatly affects the stress-strain behavior of the sample. In the case of the $4 \mathrm{~mm}$ wire, even more pronounced is the sharp decrease in the elongation of the wire until the fracture after the UTS.

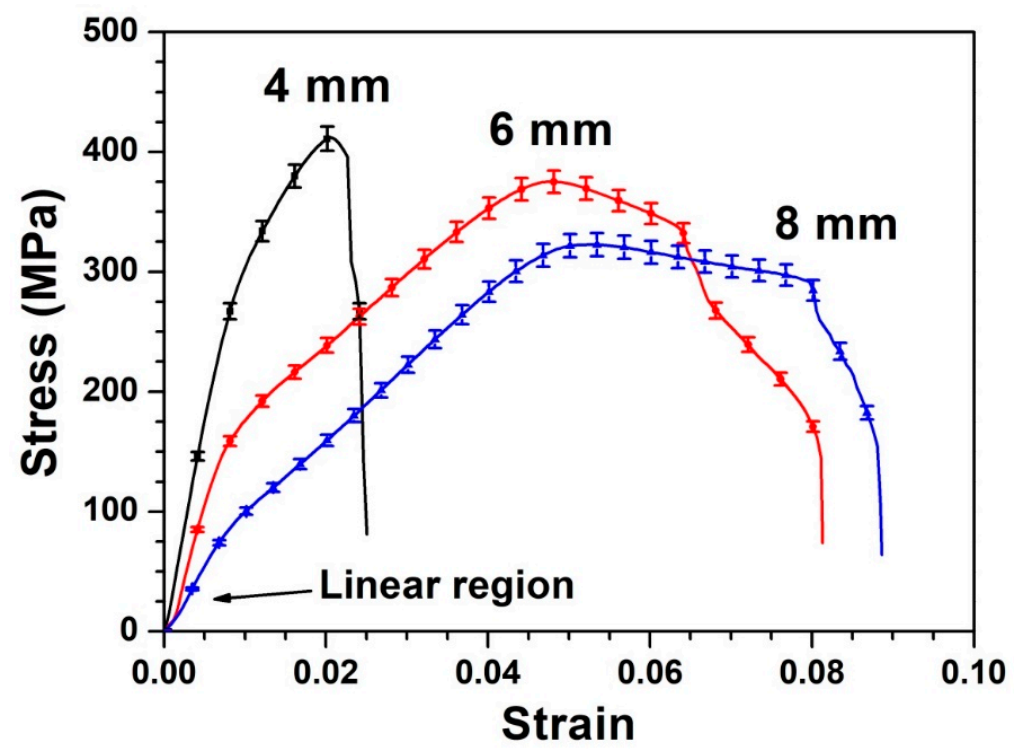

Figure 2. Stress-strain profiles for composite $\mathrm{Cu}-\mathrm{Fe}$-sheathed $\mathrm{MgB}_{2}$ wires with different outer diameters of the Fe sheath. Ultimate tensile strength (UTS) positions are marked on the curve.

Next, the comparison between the stress-strain behaviors of both types of wire samples with $4 \mathrm{~mm}$ Fe sheaths is shown in Figure 3. Note that both samples contain $\mathrm{MgB}_{2}$ cores. The results shown in the figure are therefore composite properties of the core and the sheath material. At lower stresses, both wire samples show comparable behavior. The elastic region of the Fe-sheathed wire is much greater than that of its composite counterpart. On the other hand, the plastic region is greater in the case of the $\mathrm{Cu}-\mathrm{Fe}$-sheathed wire. Above $300 \mathrm{MPa}$, the strain values of the two samples begin to differ. At $400 \mathrm{MPa}$, the strain appears to be more than $25 \%$ higher for the $\mathrm{Cu}-\mathrm{Fe}$ sheathed wire. An obvious consequence of this behavior is that our proposed $\mathrm{Cu}$ cladded wire is much more ductile, and therefore easier to draw compared with a wire with only a single sheath of Fe. 


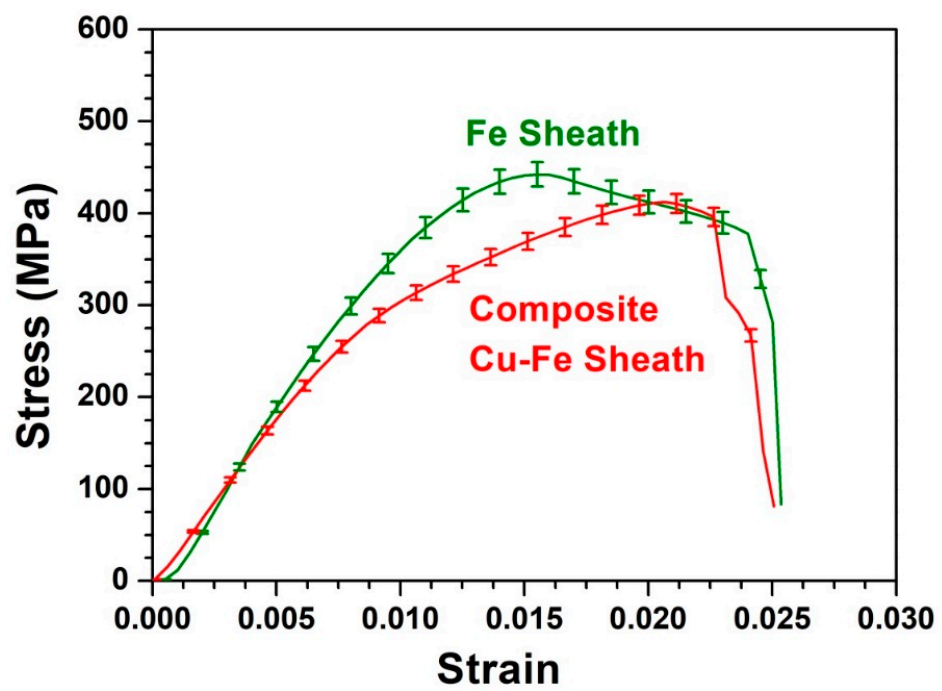

Figure 3. Comparison of stress-strain behavior of Fe-sheathed and composite $\mathrm{Cu}-\mathrm{Fe}$-sheathed $\mathrm{MgB}_{2}$ wires for Fe sheaths of $4 \mathrm{~mm}$ outer diameter. UTS positions are marked.

We carefully analyzed the stress $\neg-$ strain relationships of different samples to assess important parameters such as elastic modulus, yield strength, and ultimate tensile strength. Figure 4 highlights the lower linear region, i.e., the elastic region of the stress-strain curves shown in Figure 2. The clear increase in the slopes of the curves with the decrease in diameter is noteworthy. Note that the slope of the initial linear region of the stress-strain curve is a measure of the elastic modulus.

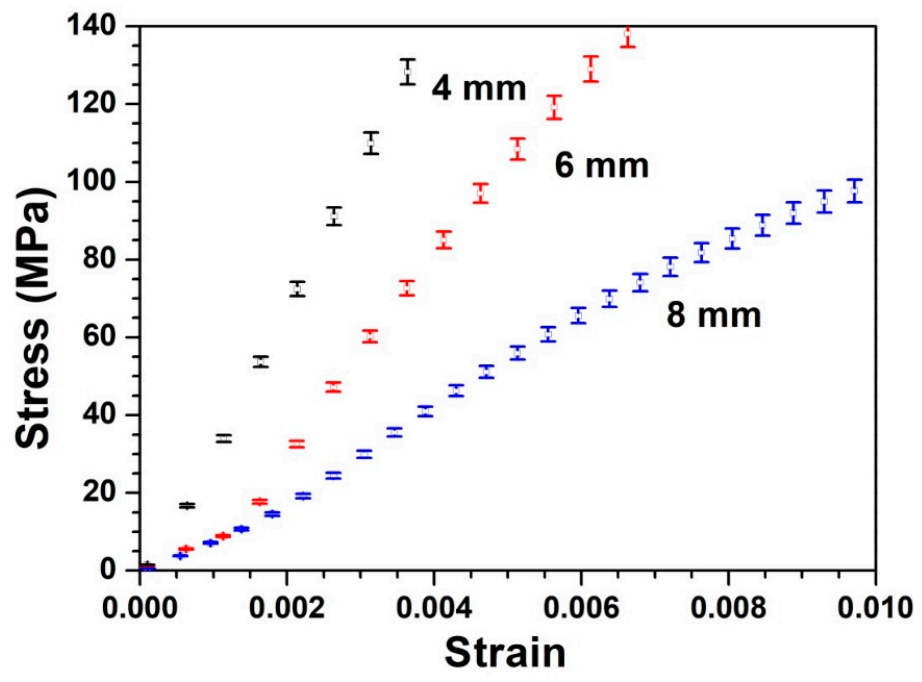

Figure 4. Stress-stain relationships of composite $\mathrm{Cu}-\mathrm{Fe}$-sheathed $\mathrm{MgB}_{2}$ wires in the elastic region for different outer diameters of the Fe sheath.

Figure 5 shows the results of the elastic modulus as a function of diameter reduction using wires at different stages of the drawing process. For both kinds of samples, the elastic modulus clearly increases with the reduction of diameter because the drawing process introduces defects into the samples, leading to an increase in the elastic modulus. The slope of the composite $\mathrm{Cu}-\mathrm{Fe}$-sheathed wire is lower than that of the Fe sheathed wire. As a consequence, owing to the decrease in elastic modulus after a certain number of drawing steps, the $\mathrm{Cu}-\mathrm{Fe}$-sheathed wire will be easier to draw than the Fe-sheathed wire and will not require an intermediate annealing step. Moreover, the final finished composite $\mathrm{Cu}-\mathrm{Fe}$ wire will be easier to wind into a solenoid for use in magnetic resonance imaging (MRI) machines or other practical applications. 


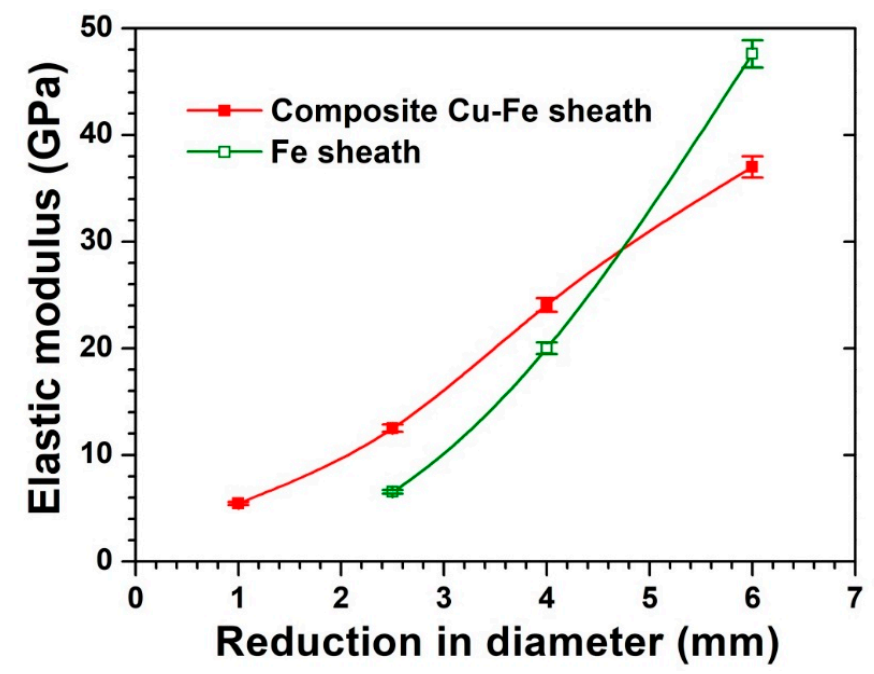

Figure 5. Dependence of elastic modulus on change in diameter for Fe sheath and composite $\mathrm{Cu}-\mathrm{Fe}$ sheath samples.

An important parameter of interest in the fabrication of wire is the yield point of the sheath material. In most of the stress-strain curves of our samples, the yield point was not well defined. Therefore, the offset yield strength was calculated where the stress causes a permanent strain of $0.2 \%$ [16]. To this end, a line was drawn parallel to the linear region of the elastic limit such that it crossed the strain axis at 0.002 . The point at which this line meets the stress-strain curve was taken as the offset yield strength. Figure 6 shows the offset yield strength for both Fe-sheathed and composite $\mathrm{Cu} / \mathrm{Fe}$-sheathed $\mathrm{MgB}_{2}$ wires as a function of diameter reduction. A closer look at the figure reveals that Fe-sheathed wires show a higher yield strength at higher diameter reduction, which is attained only after several repeated stages of drawing. Therefore, Fe-sheathed wires would require greater loads to undergo plastic deformation in order to reduce their diameters during the process of wire drawing. Since higher stress leads to greater work hardening and greater chances of fracture, Fe-sheathed wires are at a greater risk of breakage than the composite $\mathrm{Cu}-\mathrm{Fe}$-sheathed wires [17]. These results also indicate that the composite $\mathrm{Cu}-\mathrm{Fe}$ sheathed wire could be drawn to lower diameters without any intermediate annealing process.

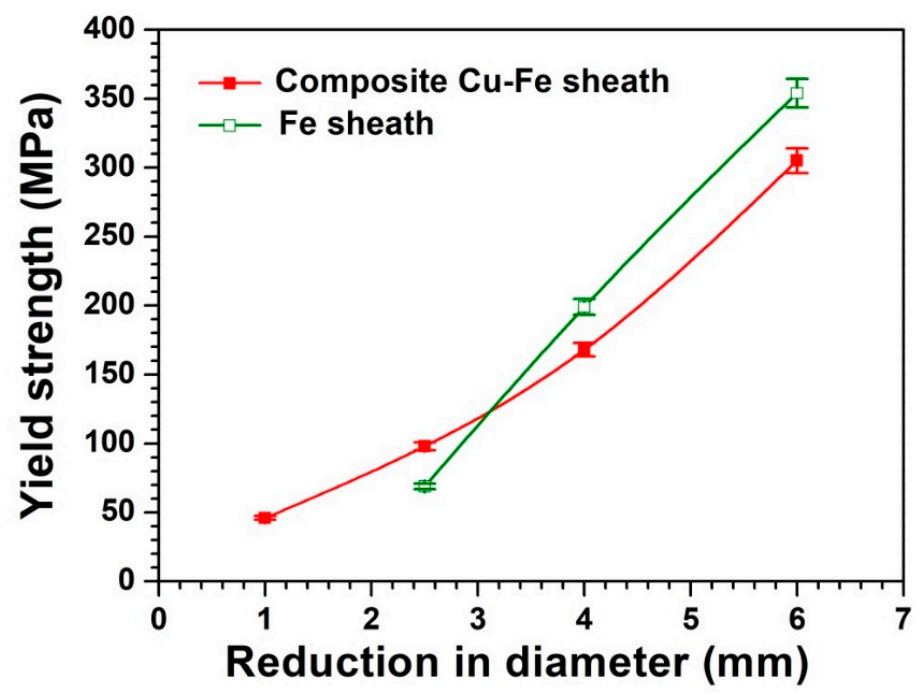

Figure 6. Yield strength for $\mathrm{Fe}$ sheath and composite $\mathrm{Cu}-\mathrm{Fe}$ sheath samples as a function of diameter reduction. 
Another parameter of interest, ultimate tensile strength, was calculated from the engineering stress-strain curves and plotted as a function of wire diameter reduction, as seen in Figure 7. In both kinds of wires, the UTS increases as the reduction in diameter increases with sequential drawing. However, the slope of the Fe-sheathed wire is much greater than that of the $\mathrm{Cu}-\mathrm{Fe}$-sheathed wire. Tensile strength is a measure of resistance to being pulled apart due to the tension. This means that composite $\mathrm{Cu}-\mathrm{Fe}$-sheathed wires required higher stress than the Fe-sheathed wires in order to undergo strain during the initial stages of drawing. It is therefore easier to pull Fe-only wires at larger diameters. But, when the wire diameter becomes smaller after several drawings, the same Fe-sheathed wire sample is relatively difficult to pull and is more prone to breaking. On the other hand, the composite $\mathrm{Cu}-\mathrm{Fe}$-sheathed wire can be drawn to a lower diameter relatively easily without breaking or requiring annealing.

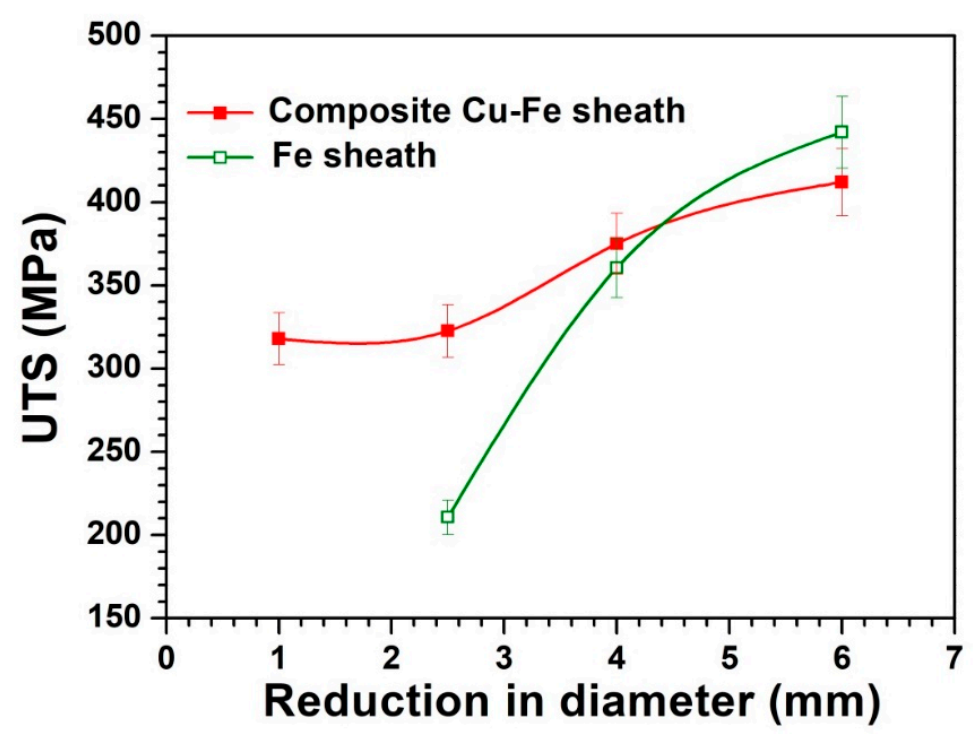

Figure 7. Ultimate tensile strength of iron tubes in Fe-sheathed and composite $\mathrm{Cu}$-Fe-sheathed $\mathrm{MgB}_{2}$ wire samples as a function of diameter reduction.

Figure 8 shows the hardness of the iron in both Fe-sheathed and composite $\mathrm{Cu}-\mathrm{Fe}$-sheathed $\mathrm{MgB}_{2}$ wires. There is a consistent trend seen for both samples in Figure 8. The hardness of both types of wire increases with the decrease in diameter of the wire. Additionally, the iron in the Fe-only wires is harder than the iron in the composite $\mathrm{Cu}-\mathrm{Fe}$ wires. Thus, the microhardness data also indicate that the drawing of composite $\mathrm{Cu}-\mathrm{Fe}$ wire is easier and less prone to the development of cracks and fractures. Hence, it can be drawn down to lower diameters without intermediate annealing. Hardness and tensile strength are generally directly proportional to one another [18]. Hardening of the metal sheath during drawing is a result of dislocations which have accumulated in the body of the metal due to permanent plastic deformation. Although hardening due to mechanical deformation is often beneficial to some extent, too great of a degree of dislocation density certainly needs to be avoided. Dislocations mostly pile up at grain boundaries, thus accelerating the weakening of the wires and consequently decreasing their mechanical strength [19]. 


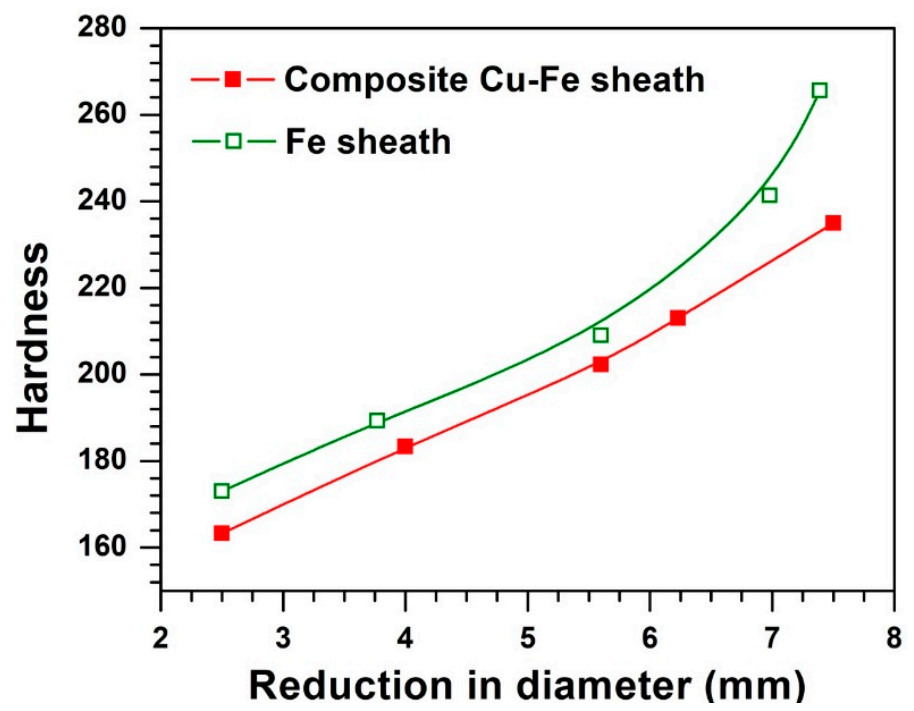

Figure 8. Hardness of Fe metal in Fe-only sheath and in composite $\mathrm{Cu}-\mathrm{Fe}$ sheath $\mathrm{MgB}_{2}$ wire samples with various diameter reductions.

To study the effect of cold mechanical work on the grains and grain boundaries of the iron sheath-which serves as the wire's main structural support-we investigated microstructures in both Fe-sheathed and composite Cu-Fe-sheathed wires. Results for samples of different diameters are shown in Figure 9. Clearly, iron grains break into smaller grains under the application of huge levels of stress during the drawing process. As the diameters of the wires decrease after every stage of drawing, the grains become smaller for both types of samples.

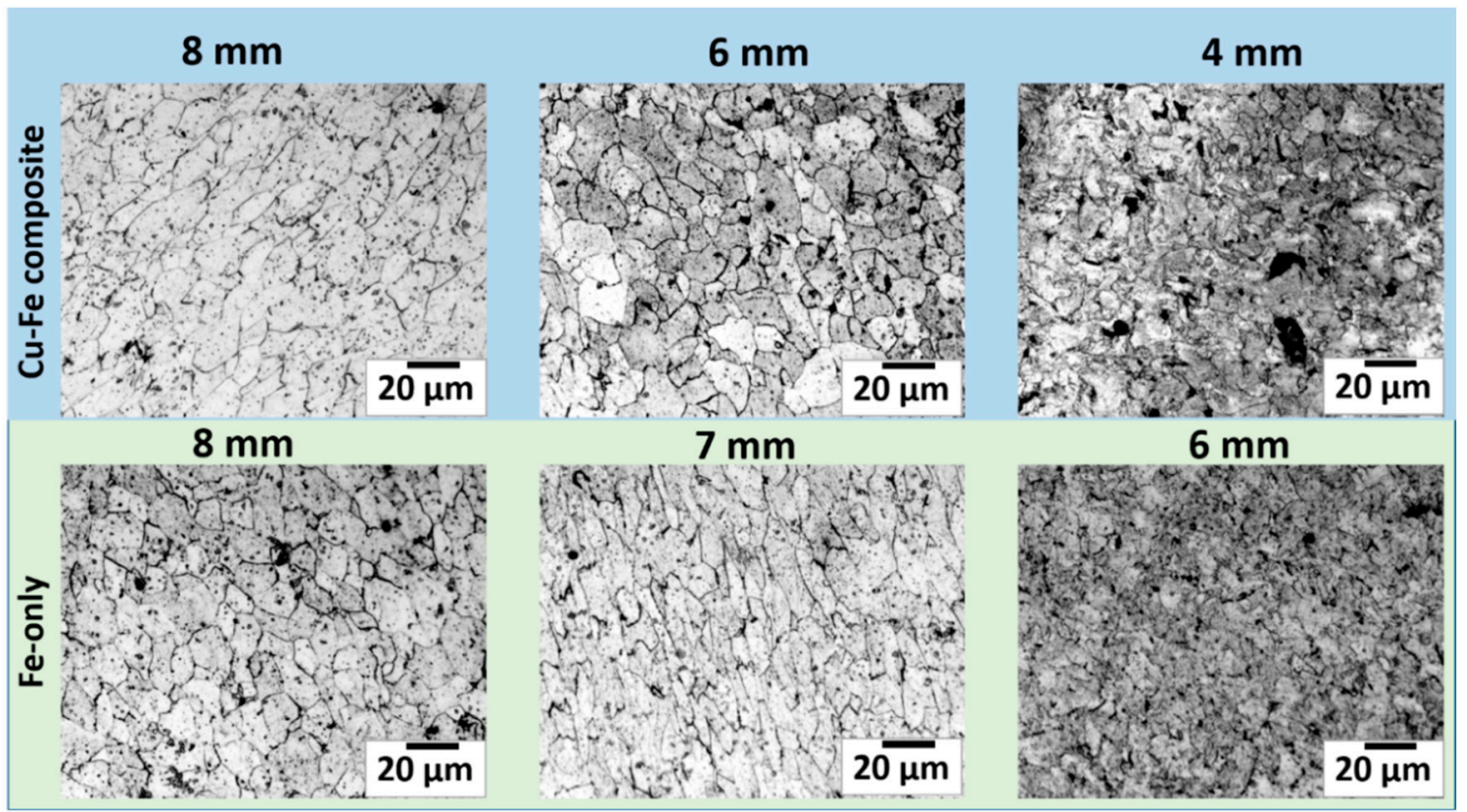

Figure 9. Optical micrographs of iron in Fe-sheathed and $\mathrm{Cu}-\mathrm{Fe}$-sheathed wire samples.

However, composite $\mathrm{Cu}-\mathrm{Fe}$-sheathed samples undergo smaller reductions in grain size than those of Fe-sheathed samples. The grain size distribution of the $8 \mathrm{~mm}$ Fe-sheathed sample is comparable to that of the $6 \mathrm{~mm}$ composite $\mathrm{Cu}-\mathrm{Fe}$-sheathed sample. On the other hand, the $4 \mathrm{~mm}$ composite $\mathrm{Cu} / \mathrm{Fe}$ sample has larger grains than those of the $6 \mathrm{~mm}$ Fe-sheath sample. These results clearly indicate that the Fe-sheathed wire has a higher rate of grain size reduction than that of the $\mathrm{Cu}-\mathrm{Fe}$-sheathed wire. 
Smaller grain size causes an increase in the grain boundaries, ultimately leading to more defects in the sample. These defects may hinder the sliding of slip planes over one another, which would increase the hardness and reduce the ductility of the material. As a result, the Fe-sheathed wire will show a rate of increase in hardness greater than that of its composite counterpart. Moreover, the Fe-sheath without $\mathrm{Cu}$ cladding is more prone to developing cracks resulting from uneven stress in the drawing process. These cracks could further propagate into larger cracks during subsequent drawing steps, eventually leading to the breaking of the wire.

The ductility of copper improves the overall malleability of the composite wire and protects the iron from fracture. The improved ductility not only prevents crack formation, but also inhibits the propagation of cracks in the Fe sheath. This could be due to the self-healing properties of such composites, where the soft copper material fills any microcracks that form in the iron sheath and prevents them from spreading $[20,21]$. This self-healing behavior is also found in laminated composites made of ceramics, metals, or polymers, where there may be single or multiple layers of different materials bonded together. This laminating effect is found to decrease the strength and increase the ductility of the composite when a ductile material is joined with a hard material. This leads to the realization of the best of both properties, namely strength and ductility. In the present work, a ductile copper layer is joined with a hard iron sheath [22-24]. This results in improvement of mechanical properties suitable for the drawing of wire without breaking. Moreover, copper may help create a more uniform distribution of stress on the iron sheath during the hammering process in a swaging machine.

It should be noted that an intermediate annealing step would require a longer processing time and would entail a higher energy consumption during wire fabrication. On the other hand, although copper cladding will increase the material cost, its use is necessary for heat dissipation due to the magnetic flux movement that occurs during the actual practical application of the superconducting wire. Therefore, the overall manufacturing process of wire with copper cladding will be cost-effective.

\section{Conclusions}

Instead of using a single material for tubes as is most commonly reported in literature, we used a composite tube. The inner layer was made of a relatively inert Fe tube, and the outer layer was a highly conductive $\mathrm{Cu}$ tube capable of efficiently dissipating heat. In order to examine the suitability of our technique of using such a composite sheath, we carefully carried out tests of tensile strength, microhardness and microstructure and evaluated key parameters of mechanical properties such as elastic modulus, yield strength, ultimate tensile strength and hardness. To get a clearer picture of the effects of the copper cladding, we also fabricated superconducting $\mathrm{MgB}_{2}$ wire using only Fe as the sheath material to make comparisons at various stages of the drawing process.

We found that the yield strength increased at a much faster rate for Fe-sheathed wire in comparison with composite $\mathrm{Cu}-\mathrm{Fe}$-sheathed wire. However, after several drawings, the composite wire exhibited lower yield strength, indicating higher ductility. We also noted that the rates of change of both elastic modulus and tensile strength were lower for composite $\mathrm{Cu}$-Fe-sheath wires than for those of Fe-sheath wires. Moreover, wires with Fe-only sheaths showed a significantly higher hardness than that of their composite $\mathrm{Cu}-\mathrm{Fe}$-sheath counterparts. Due to the improvements in the mechanical properties noted above, composite $\mathrm{Cu}$-Fe-sheath wires are less prone to fracture during the drawing process for fabrication of long wires and do not require intermediate annealing steps.

This conclusion is further supported by microstructural studies, which show that the rate of decrease in grain size and increase in grain boundaries, and hence the increase in defects, was more pronounced in the cases of the Fe-sheathed samples. These defects may hinder the sliding of slip planes over one another, which would increase the hardness and reduce the ductility of the material. On the other hand, the ductility of copper improves the overall malleability of the composite wire. Moreover, it protects the iron from fracture because of the laminating effect produced by the copper cladding on the iron sheath. In addition, copper imparts uniform stress distribution on the iron sheath during the hammering process involved in swaging and drawing. 
In the cold drawing process for superconducting wires, the use of a coolant is generally avoided, as it may affect the superconducting material in the core by causing an inadvertent chemical reaction. In the present strategy, the use of copper cladding aids in the faster and more uniform distribution and dissipation of heat that builds up after multiple successive drawing steps in the absence of a coolant.

Author Contributions: Conceptualization, M.S. and N.A.M.; methodology, M.S., N.A.M.; software, M.S., N.A.M.; validation, M.S., N.A.M., N.S.A.; formal analysis, M.S., N.A.M., M.A.; investigation, M.S., N.A.M., M.L., T.B.; resources, M.S., N.S.A.; experimental, N.A.M., M.L., T.B.; writing-original draft preparation, M.S., N.A.M., M.A.; writing-review and editing, M.S., M.A.; visualization, M.S., N.A.M.; supervision, M.S.; project administration, M.S., N.S.A.; Funding acquisition, M.S., N.S.A., M.A.

Funding: This research was funded by the King Abdulaziz City of Science and Technology (KACST), Saudi Arabia, through the research grant number AT 34-174.

Conflicts of Interest: The authors declare no conflict of interest.

\section{References}

1. Nagamatsu, J.; Nakagawa, N.; Muranaka, T.; Zenitani, Y.; Akimitsu, J. Superconductivity at $39 \mathrm{~K}$ in magnesium diboride. Nature 2001, 410, 63. [CrossRef]

2. Larbalestier, D.; Cooley, L.; Rikel, M.; Polyanskii, A.; Jiang, J.; Patnaik, S.; Cai, X.; Feldmann, D.; Gurevich, A.; Squitieri, A. Strongly linked current flow in polycrystalline forms of the superconductor MgB 2. Nature 2001, 410, 186. [CrossRef] [PubMed]

3. Flukiger, R.; Suo, H.L.; Musolino, N.; Beneduce, C.; Toulemonde, P.; Lezza, P. Superconducting properties of MgB2 tapes and wires. Phys. C Supercond. 2003, 385, 286-305. [CrossRef]

4. Alessandrini, M.; Fang, H.; Hanna, M.; Putman, P.; Zhou, Y.X.; Salama, K. High critical current of Ti-sheathed MgB2 wires for AC and weight-critical applications. Supercond. Sci. Technol. 2006, 19, 129-132. [CrossRef]

5. Fang, H.; Xue, Y.Y.; Zhou, Y.X.; Baikalov, A.; Salama, K. Densification of MgB2 cores in iron-clad tapes. Supercond. Sci. Technol. 2004, 17, L27-L29. [CrossRef]

6. Liang, G.; Fang, H.; Katz, D.; Tang, Z.; Salama, K. Phase formation in Cu-sheathed MgB2 wires. Phys. C Supercond. 2006, 442, 113-123. [CrossRef]

7. Sumption, M.D.; Bhatia, M.; Rindfleisch, M.; Tomsic, M.; Collings, E.W. Transport properties of multifilamentary, in situ route, Cu-stabilized MgB2 strands: One metre segments and the J(c)(B, T) dependence of short samples. Supercond. Sci. Technol. 2006, 19, 155-160. [CrossRef]

8. Glowacki, B.; Majoros, M.; Vickers, M.; Evetts, J.; Shi, Y.; McDougall, I. Superconductivity of powder-in-tube MgB2 wires. Supercond. Sci. Technol. 2001, 14, 193. [CrossRef]

9. Schlachter, S.I.; Frank, A.; Ringsdorf, B.; Orschulko, H.; Obst, B.; Liu, B.; Goldacker, W. Suitability of sheath materials for MgB2 powder-in-tube superconductors. Phys. C Supercond. Appl. 2006, 445, 777-783. [CrossRef]

10. Kovac, P.; Husek, I.; Melisek, T.; Kulich, M.; Strbik, V. MgB2 composite wires with Fe, Nb and Ta sheaths. Supercond. Sci. Technol. 2006, 19, 600-605. [CrossRef]

11. Flukiger, R.; Lezza, P.; Beneduce, C.; Musolino, N.; Suo, H.L. Improved transport critical current and irreversibility fields in mono- and multifilamentary Fe/MgB2 tapes and wires using fine powders. Supercond. Sci. Technol. 2003, 16, 264-270. [CrossRef]

12. Ulgen, A.T.; Belenli, I. The Effect of Fe Diffusion on Some Physical and Superconducting Properties of MgB2. J. Supercond. Nov. Magn. 2017, 30, 1089-1095. [CrossRef]

13. Ulgen, A.T.; Belenli, I. Sintering Time Dependence of Iron Diffusion in MgB2 and Its Effect on Superconducting Properties. AIP Conf. Proc. 2017, 1815, 040008. [CrossRef]

14. Hammond, C.R. The Elements. In Handbook of Chemistry and Physics, 81st ed.; CRC Press: Boca Raton, FL, USA, 2004.

15. Wozniak, M.; Hopkins, S.C.; Gajda, D.; Glowacki, B.A. The effect of copper additions in the synthesis of in situ MgB2 Cu-sheathed wires. Phys. C Supercond. 2012, 477, 66-73. [CrossRef]

16. Roylance, D.; Cohen, K.C.; Jenkins, C.H.; Khanna, S.K. Mechanics of materials: A materials science perspective. Proc. Inst. Mech. Eng. Part L J Mater. Des. Appl. 2001, 215, 141-145. [CrossRef]

17. Yang, M.X.; Pan, Y.; Yuan, F.P.; Zhu, Y.T.; Wu, X.L. Back stress strengthening and strain hardening in gradient structure. Mater. Res. Lett. 2016, 4, 145-151. [CrossRef] 
18. Gaško, M.; Rosenberg, G. Correlation between hardness and tensile properties in ultra-high strength dual phase steels-short communication. Mater. Eng. 2011, 18, 155-159.

19. Karaboğa, F.; Ulgen, A.T.; Yetiş, H.; Akdoğan, M.; Pakdil, M.; Belenli, I. Mechanical properties and uniformity of Fe-MgB2 wires upon various wire drawing steps. Mater. Sci. Eng. A 2018, 721, 89-95. [CrossRef]

20. Beiermann, B.A.; Keller, M.W.; Sottos, N.R. Self-healing flexible laminates for resealing of puncture damage. Smart Mater. Struct. 2009, 18, 085001. [CrossRef]

21. Sun, J.L.; Liu, C.X.; Zhang, R.; Gong, F.; Wang, C.; Li, G. Comprehensive effect of the mechanical properties, laminated structure and healing conditions on the self-healing behaviors of laminated $\mathrm{Al} 2 \mathrm{O} 3-\mathrm{MgO}$ ceramic composites. Ceram. Int. 2019, 45, 13597-13604. [CrossRef]

22. Serror, M.H.; Inoue, J. Analytical Study for Deformability of Laminated Sheet Metal with Full Interfacial Bond. J. Eng. Mech. 2013, 139, 94-103. [CrossRef]

23. Qiu, Y.X.; Kaden, N.; Schmidtchen, M.; Prahl, U.; Biermann, H.; Weidner, A. Laminated TRIP/TWIP Steel Composites Produced by Roll Bonding. Metals 2019, 9, 195. [CrossRef]

24. Lesuer, D.R.; Syn, C.K.; Sherby, O.D.; Wadsworth, J.; Lewandowski, J.J.; Hunt, W.H. Mechanical behaviour of laminated metal composites. Int. Mater. Rev. 1996, 41, 169-197. [CrossRef]

(C) 2019 by the authors. Licensee MDPI, Basel, Switzerland. This article is an open access article distributed under the terms and conditions of the Creative Commons Attribution (CC BY) license (http://creativecommons.org/licenses/by/4.0/). 